See discussions, stats, and author profiles for this publication at: https://www.researchgate.net/publication/289523010

\title{
Acute administration of high doses of taurine does not substantially improve high-intensity running performance and the effect on maximal accumulated oxygen deficit is unclear
}

Article in Applied Physiology Nutrition and Metabolism · January 2016

DOI: 10.1139/apnm-2015-0435

CITATIONS

14

6 authors, including:

Fabio Milioni

São Paulo State University

30 PUBlications 105 Citations

SEE PROFILE

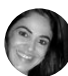

Ellen Cristini de Freitas

University of São Paulo

30 PUBLICATIONS 252 CITATIONS

SEE PROFILE

Some of the authors of this publication are also working on these related projects:

Mitochondrial energetic metabolism in adipocytes of obese women View project

Journal of Sports Sciences: Special Issue Table Tennis View project
READS

355

Elvis de Souza Malta

São Paulo State University

18 PUBliCATIONS 44 CITATIONS

SEE PROFILE

Alessandro Moura Zagatto

São Paulo State University

154 PUBLICATIONS 1,119 CITATIONS

SEE PROFILE 


\title{
Acute administration of high doses of taurine does not substantially improve high-intensity running performance and the effect on maximal accumulated oxygen deficit is unclear
}

\author{
Fabio Milioni, Elvis de Souza Malta, Leandro George Spinola do Amaral Rocha, \\ Camila Angélica Asahi Mesquita, Ellen Cristini de Freitas, and Alessandro Moura Zagatto
}

\begin{abstract}
The aim of the present study was to investigate the effects of acute administration of taurine overload on time to exhaustion (TTE) of high-intensity running performance and alternative maximal accumulated oxygen deficit $\left(\mathrm{MAOD}_{\mathrm{ALT}}\right)$. The study design was a randomized, placebo-controlled, crossover design. Seventeen healthy male volunteers (age: $25 \pm 6$ years; maximal oxygen uptake: $50.5 \pm 7.6 \mathrm{~mL} \cdot \mathrm{kg}^{-1} \cdot \mathrm{min}^{-1}$ ) performed an incremental treadmill-running test until voluntary exhaustion to determine maximal oxygen uptake and exercise intensity at maximal oxygen uptake. Subsequently, participants completed randomly 2 bouts of supramaximal treadmill-running at 110\% exercise intensity at maximal oxygen uptake until exhaus-

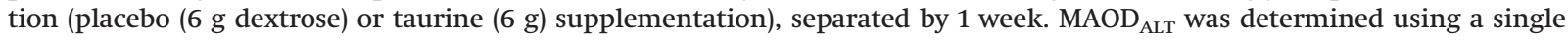
supramaximal effort by summating the contribution of the phosphagen and glycolytic pathways. When comparing the results of the supramaximal trials (i.e., placebo and taurine conditions) no differences were observed for high-intensity running TTE $(237.70 \pm 66.00$ and $277.30 \pm 40.64 \mathrm{~s} ; p=0.44)$ and $\mathrm{MAOD}_{\mathrm{ALT}}\left(55.77 \pm 8.22\right.$ and $\left.55.06 \pm 7.89 \mathrm{~mL} \cdot \mathrm{kg}^{-1} ; p=0.61\right)$, which seem to indicate trivial and unclear differences using the magnitude-based inferences approach, respectively. In conclusion, acute $6 \mathrm{~g}$ taurine supplementation before exercise did not substantially improve high-intensity running performance and showed an unclear effect on $\mathrm{MAOD}_{\mathrm{ALT}}$.
\end{abstract}

Key words: anaerobic capacity, EPOC, high-intensity exercise, MAOD, lactate.

Résumé : Cette étude a pour objectif d'examiner les effets de l'administration ponctuelle d'une surcharge de taurine sur le temps d'épuisement ("TTE ») lors d'une course d'intensité élevée et sur le maximal alternatif deficit d'oxygène accumulé ( $\mathrm{MAOD}_{\mathrm{ALT}}$ »). On utilise pour cette étude un devis aléatoire croisé avec groupe placebo. Dix-sept volontaires masculins (âge, $25 \pm$ 6 ans, consommation maximale d'oxygène : $50,5 \pm 7,6 \mathrm{~mL} \cdot \mathrm{kg}^{-1} \cdot \mathrm{min}^{-1}$ ) participent à un test d'effort progressif sur tapis roulant jusqu'à épuisement pour la détermination de la consommation maximale d'oxygène et l'intensité d'exercice à la consommation maximale d'oxygène. Par la suite, les sujets participent aléatoirement à une semaine d'intervalle à deux séances de course supramaximale sur tapis roulant à une intensité équivalente à $110 \%$ l'intensité d'exercice à la consommation maximale d'oxygène jusqu'à épuisement (supplément de $6 \mathrm{~g}$ d'un placebo (dextrose) ou de taurine). On détermine le MAOD $\mathrm{ALT}_{\mathrm{Au}}$ cours d'un seul effort supramaximal en additionnant la contribution de la phosphagénolyse et de la glycolyse. En comparant les données des essais supramaximaux (conditions placebo et taurine), on n'observe aucune différence de TTE (237,70 $\pm 66,00 \mathrm{~s}$ et $277,30 \pm 40,64 \mathrm{~s} ; p=0,44)$ et de $\mathrm{MAOD}_{\mathrm{ALT}}\left(55,77 \pm 8,22\right.$ et $\left.55,06 \pm 7,89 \mathrm{~mL} \cdot \mathrm{kg}^{-1} ; p=0,61\right)$, ce qui semble indiquer des différences futiles et minimes compte tenu de l'approche inférentielle de l'ampleur des différences respectivement. En conclusion, la supplémentation ponctuelle de $6 \mathrm{~g}$ de taurine avant l'exercice n'améliore pas substantiellement la performance à la course d'intensité élevée et révèle un effet incertain sur le $\mathrm{MAOD}_{\mathrm{ALT}}$. [Traduit par la Rédaction]

Mots-clés : capacité anaérobie, EPOC, exercice d'intensité élevée, MAOD, lactate.

\section{Introduction}

Taurine is a sulfonated $\beta$-amino acid (2-aminoethane sulfonic acid), which is broadly used as a nutritional supplement, especially in energy drinks where it is combined with other substances. Energy drinks are generally composed of different ingredients, among them carbohydrates and caffeine, which are known to enhance performance effects (Astorino et al. 2009; Stellingwerff and Cox 2014). The concomitant administration of several stimulants and substances that improve performance disguises identification of the true effects of taurine on sports performance.
Previous studies have investigated the positive ergogenic effects of the acute administration of these types of drinks on endurance performance (60 $\mathrm{min}$ at $\sim 70 \%$ of intensity at maximal oxygen uptake $\left(\mathrm{iVO} \mathrm{O}_{2 \max }\right)$, followed by an incremental phase of $50 \mathrm{~W}$ every 3 min until exhaustion) (Gei $\beta$ et al. 1994), time trial (Ivy et al. 2009), time to exhaustion (TTE) (Walsh et al. 2010), and anaerobic efforts (Alford et al. 2001). In relation to the effects of isolated taurine administration on sports performance, the best results have been found after periods of chronic supplementation (Zhang et al. 2004; da Silva et al. 2014). Zhang et al. (2004) showed an increase in maximal oxygen uptake $\left(\dot{V}_{2 \max }\right)$, TTE, and power out-

Received 19 August 2015. Accepted 4 January 2016.

F. Milioni, E.S. Malta, and A.M. Zagatto. Laboratory of Physiology and Human Performance, UNESP - Univ Estadual Paulista, Rio Claro, São Paulo, Brazil; Department of Physical Education, UNESP - Univ Estadual Paulista, Rio Claro, São Paulo, Brazil.

L.G.S.A. Rocha and C.A.A. Mesquita. Department of Physical Education, UNESP - Univ Estadual Paulista, Rio Claro, São Paulo, Brazil.

E.C. de Freitas. School of Physical Education and Sports of Ribeirão Preto, University of São Paulo, Ribeirão Preto, São Paulo, Brazil.

Corresponding author: Alessandro Moura Zagatto (email: azagatto@yahoo.com.br). 
put obtained during an incremental cycling test after 7 days of $6 \mathrm{~g}$ taurine supplementation.

However, few studies have investigated the effects of acute intake of taurine on sports performance. It is important to note that the positive effects of taurine appear to be linked not only to the period of administration but also to the dosage (Miyazaki et al. 2004). Rutherford et al. (2010) found no significant effects of acute low-dosage taurine ingestion (1.66 g taurine) on time-trial performance in well-trained cyclists (at $5 \mathrm{~kJ}$ of work $\mathrm{kg}^{-1}$ body mass) performed after $90 \mathrm{~min}$ of submaximal endurance cycling exercises (at $66.5 \pm 1.9 \%$ of $\dot{V} \mathrm{O}_{2 \max }$ ).

The exact mechanisms by which taurine enhances exercise performance are unclear; however, animal studies have indicated the following possibilities: (i) decrement of oxidative stress (Miyazaki et al. 2004); (ii) increase in $\mathrm{Ca}^{2+}$ release into the muscle interstitial space (Dutka et al. 2014); (iii) stabilization and hyperexcitement of the cell membrane (Yatabe et al. 2003); and (iv) decrease in blood lactate accumulation during exercise $\left(90 \mathrm{~min}\right.$ at $10 \mathrm{~m} \cdot \mathrm{min}^{-1}$; then increasing by $5 \mathrm{~m} \cdot \mathrm{min}^{-1}$ each $15 \mathrm{~min}$ until exhaustion in mice) (Imagawa et al. 2009). The latter phenomenon directly influences the amount of energy provided by the glycolytic pathway during high-intensity exercise and thereby the anaerobic capacity.

To assess anaerobic capacity, the maximal accumulated oxygen deficit method (MAOD) is considered the most widely accepted test (Medbø et al. 1988; Noordhof et al. 2010). The MAOD represents the difference between the predicted accumulated oxygen demand of a supramaximal exercise bout (i.e., obtained from the linear relationship between submaximal exercise intensities and the respective oxygen uptake $\left.\left(\mathrm{VO}_{2}\right)\right)$ and the measured accumulated $\dot{V} \mathrm{O}_{2}$ during the supramaximal exercise bout (see Noordhof et al. 2010, 2011, for more details).

The original protocol is a time-consuming procedure and the

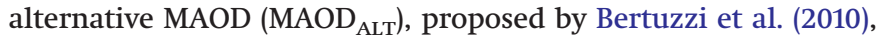
has been shown to be a good and fast alternative. Basically, MAOD $_{\text {ALT }}$ consists of the sum of the oxygen equivalents from the phosphagen and glycolytic pathways estimated in a single supramaximal effort, analyzing the fast phase of excess postexercise oxygen consumption EPOC $_{\mathrm{FAST}}$; phosphagen system contribution) and the net blood lactate responses ( $\Delta[\mathrm{La}]$; subtracting the peak and resting values) (Bertuzzi et al. 2010; Zagatto et al. 2011; Brisola et al. 2015). $\mathrm{MAOD}_{\mathrm{ALT}}$ has been shown to be a reliable method (intraclass correlation $=0.87$ ) (Zagatto et al. in press ${ }^{1}$ ).

If a low dosage of taurine ingestion (i.e., less than $2 \mathrm{~g}$ ) decreases lactate accumulation (Imagawa et al. 2009) during submaximal exercise, a high dosage of taurine administration may exert ben-

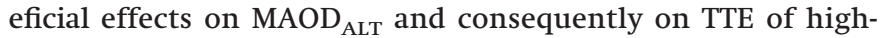
intensity running performance. In this way, the aim of the present study was to investigate the effects of acute high-dosage taurine administration (i.e., $6.0 \mathrm{~g}$ ) on TTE performance and MAOD $\mathrm{ALT}_{\text {. }}$

\section{Materials and methods}

\section{Participants}

The sample size was calculated based on the assumption that taurine supplementation enhances performance (Gei $\beta$ et al. 1994). G*Power software version 3.0.10 (Heinrich-Heine University, Düsseldorf, Germany) was used to determine that a sample size of 10 subjects was the minimum needed to provide a statistical power of $90 \%$ with an alpha of 0.05 for the analysis.

The study included 17 recreationally trained (according to De Pauw et al. 2013) male participants (age: $26 \pm 5$ years; body mass: $77.8 \pm$ $9.0 \mathrm{~kg}$; height: $171.4 \pm 28.6 \mathrm{~cm}$; fat percentage: $19.3 \% \pm 5.6 \%$; $\left.\dot{V} \mathrm{O}_{2 \max }: 50.5 \pm 7.6 \mathrm{~mL} \cdot \mathrm{kg}^{-1} \cdot \mathrm{min}^{-1}\right)$. All participants were instructed to consume a light meal about $2 \mathrm{~h}$ before the test, not to perform any strenuous exercise, and not to ingest caffeine or other stimulating substances in the $48 \mathrm{~h}$ before the experiments. None of the participants were engaged in any competitive training program, but practiced 2-4 times per week for recreational sports (jogging, swimming, and soccer) for at least 1 year. All participants were informed of the possible risks and benefits of the tests and signed an informed consent form. All experimental procedures were approved by the Ethics Committee of São Paulo State University and were conducted according to the Declaration of Helsinki.

\section{Experimental design}

The present study was a randomized, placebo-controlled, crossover design. Body composition was assessed by double energy X-ray absorptiometry (Discovery, Hologic, USA). Prior to all tests the participants completed 5-7 min of warm-up by running on a motorized treadmill (ATL, Inbrasport, Porto Alegre, Brazil) at submaximal intensity $\left(7.5 \mathrm{~km} \cdot \mathrm{h}^{-1}\right)$ in a laboratory under controlled conditions $\left(43.8 \% \pm 6.3 \%\right.$ relative humidity and $22.9 \pm 1.3{ }^{\circ} \mathrm{C}$ temperature). After $5 \mathrm{~min}$ of passive recovery, an incremental treadmill-running test was performed until voluntary exhaustion for determination of $\dot{V} \mathrm{O}_{2 \max }$ and the $\mathrm{i} \dot{V} \mathrm{O}_{2 \max }$. Finally, supramaximal treadmill-running bouts $\left(110 \%\right.$ of $\left.\mathrm{i} \mathrm{O}_{2 \max }\right)$ were performed until voluntary exhaustion with randomized crossover supplementation (placebo (6 g dextrose) or taurine (6 g) supplementation) to determine the $\mathrm{MAOD}_{\mathrm{ALT}}$ (Bertuzzi et al. 2010; Zagatto and Gobatto 2012). Treadmill gradient was set at $1 \%$. Trials were separated by 1 week to provide a sufficient wash-out period (Galloway et al. 2008). Verbal encouragement was provided in all tests together with a safety chest belt to prevent falls and to ensure that the participants felt safe to reach maximal effort at voluntary exhaustion. A schematic overview of the experimental protocol is provided in Fig. 1.

\section{Data collection and processing}

During the incremental treadmill-running test and the 2 supramaximal efforts, $\dot{V} \mathrm{O}_{2}$ was measured breath-by-breath using an ergospirometer (Quark PFT, Cosmed, Rome, Italy). Before the beginning of the evaluation, the ergospirometer was calibrated with a high-precision gas mixture $\left(16 \% \mathrm{O}_{2}\right.$ and $5 \% \mathrm{CO}_{2}$, balanced $\mathrm{N}_{2}$; White Martins, Osasco, Brazil) and ambient air sample, whereas the ventilometer was calibrated before exercise and verified after exercise using a 3-L calibration syringe (Hans-Rudolph, Shawnee, Kans., USA), in accordance with the manufacturer's instructions. For analysis of $\dot{V O}_{2}$ respiratory variables, the data were smoothed every 5 points and interpolated every $1 \mathrm{~s}$ to eliminate outlying data (Özyener et al. 2001) using the software OriginPro 8.0 (OriginLab Corp., Northampton, Mass., USA). Heart rate (HR) was measured using a transmitter belt coupled to the gas analyzer (wireless HR 138 monitor; Cosmed).

Blood samples were collected $(25 \mu \mathrm{L})$ from the earlobe at 3, 5, and $7 \mathrm{~min}$ after each test to determine peak blood lactate concentration. For the supramaximal efforts, blood samples were also collected at rest to estimate delta lactate concentration (i.e., peak minus rest). The samples were analyzed in an electrochemical lactimeter YSI 2300 STAT (Yellow Spring Instruments, Yellow Spring, Ohio, USA).

\section{Incremental treadmill-running test}

The incremental treadmill-running test started at $8 \mathrm{~km} \cdot \mathrm{h}^{-1}$ with increments of $1.5 \mathrm{~km} \cdot \mathrm{h}^{-1}$ every $2 \mathrm{~min}$. $\dot{V} \mathrm{O}_{2 \max }$ is the highest average $\dot{V} \mathrm{O}_{2}$ obtained during the final $20 \mathrm{~s}$ of each exercise stage, if at least 2 of the following criteria were observed: (i) $\dot{V O}_{2}$ stabilization in the last 2 stages (range $<2.1 \mathrm{~mL} \cdot \mathrm{kg}^{-1} \cdot \mathrm{min}^{-1}$ ); (ii) respiratory exchange ratio $>1.10$; (iii) maximum $\mathrm{HR}>90 \%$ of maximum pre- 
Fig. 1. Experimental study design (schematic schedule of application of the protocols). TTE, time to exhaustion; $\mathrm{iVO}_{2 \mathrm{MAX}}$, exercise intensity at maximal oxygen uptake.

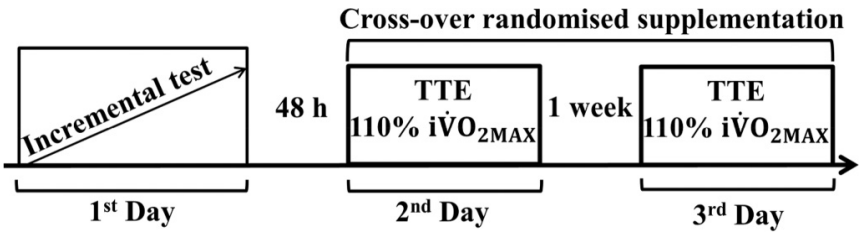

dicted HR; and (iv) peak blood lactate concentration $\geq 8.0 \mathrm{mmol} \cdot \mathrm{L}^{-1}$, as suggested by Howley et al. (1995). If at least $2 \dot{\mathrm{V}} \mathrm{O}_{2 \max }$ criteria were not observed, the incremental treadmill-running test was applied again. The $\mathrm{iVO}_{2 \max }$ was assumed to be the lowest speed of the incremental stages, during which the $\mathrm{VO}_{2 \max }$ was reached.

\section{Supramaximal test and MAOD ${ }_{\mathrm{ALT}}$ determination}

The participants performed 2 identical supramaximal efforts separated by 1 week, 1 ingesting a placebo supplement and the other ingesting a taurine supplement in a randomized, placebocontrolled, crossover design.

Prior to any effort, the participants remained seated for $10 \mathrm{~min}$ to determine the $\dot{V} \mathrm{O}_{2}$ baseline $\left(\dot{V}_{2 \mathrm{BASE}}\right)$ and resting blood lactate concentration (i.e., samples collected after $10 \mathrm{~min}$ of sitting). The supramaximal test intensity was $110 \%$ of $\mathrm{iVO}_{2 \max }$ (Weber and Schneider 2001; Bertuzzi et al. 2010). The TTE was measured and after the end of the test the $\dot{V} \mathrm{O}_{2}$ responses were measured for another $7 \mathrm{~min}$ to determine the $\mathrm{EPOC}_{\mathrm{FAST}}$.

$\mathrm{MAOD}_{\mathrm{ALT}}$ is based on the sum of the oxygen equivalents from the glycolytic $\left(W_{\text {[La] }}\right)$ and phosphagen $\left(W_{\mathrm{PCR}}\right)$ energy systems. The EPOC $_{\text {FAST }}$ was used to estimate the contribution of the $W_{\mathrm{PCR}}$, calculated using a biexponential mathematical fit (eq. 1) (OriginPro 8.0 software; OriginLab Corp.) (Zagatto and Gobatto 2012).

$$
\dot{V} \mathrm{O}_{2(t)}=\dot{V} \mathrm{O}_{2 \text { base }}+A_{1}\left[\mathrm{e}^{-(t-\delta) / \tau_{1}}\right]+A_{2}\left[\mathrm{e}^{-(t-\delta) / \tau_{2}}\right]
$$

where $\dot{V} \mathrm{O}_{2(t)}$ is the oxygen uptake at time $t, A$ is the amplitude, $\delta$ is the time delay, and $\tau$ is the time constant. 1 and 2 represent the fast and slow components, respectively, and the $\mathrm{EPOC}_{\mathrm{FAST}}$ was calculated by the product of $A_{1}$ and $\tau_{1}$.

The contribution of the glycolytic pathway was estimated by the net blood lactate concentration, measured by subtracting the resting values from the peak lactate after the test, considering for each $1 \mathrm{mmol} \cdot \mathrm{L}^{-1}$ of the blood lactate variation an equivalent of $3 \mathrm{~mL} \cdot \mathrm{kg}^{-1}$ of oxygen (Di Prampero and Ferretti 1999).

\section{Placebo and taurine supplementation}

On the days of the supramaximal treadmill-running tests, the participants ingested $6 \mathrm{~g}$ of taurine or placebo (dextrose) at $90 \mathrm{~min}$ prior to the exhaustive test. Galloway et al. (2008) verified an $\sim 7$-fold increase in plasma taurine concentration after $90 \mathrm{~min}$ of $1.66 \mathrm{~g}$ supplementation. The taurine was obtained from Ajinomoto (2-aminoethane sulfonic acid, 99\% pure; Ajinomoto Co., Inc., Limeira, SP, Brazil), and the dosage was adapted from Zhang et al. (2004). The capsules were produced at the pharmacy of the University Hospital and both supplements were administered in identical capsules of $1 \mathrm{~g}$ with $\sim 500 \mathrm{~mL}$ water. Dextrose (i.e., carbohydrate) was chosen as the placebo supplement because the dosage used represented a minimal possibility of influences on performance, since 30-60 g of acute carbohydrate supplementation are needed for performance effects (Baker et al. 2015).

\section{Statistical analysis}

For the statistical analysis, the software IBM SPSS Statistics 20 (IBM Corp., Germany) was used. Initially, all variables were examined by Kolmogorov-Smirnov test for normal distribution. The
Table 1. Mean \pm SD of time to exhaustion, blood lactate, and oxygen uptake measured during supramaximal efforts under placebo and taurine supplementation.

\begin{tabular}{lrrrl}
\hline & \multicolumn{1}{c}{ Placebo } & \multicolumn{1}{l}{ Taurine } & \multicolumn{1}{l}{$\%$} & \multicolumn{1}{l}{$p$} \\
\hline TTE $(\mathrm{s})$ & $237.7 \pm 66.0$ & $244.7 \pm 58.3$ & 2.9 & 0.44 \\
{$[\mathrm{La}]_{\text {BASE }}\left(\mathrm{mmol} \cdot \mathrm{L}^{-1}\right)$} & $1.0 \pm 0.2$ & $1.0 \pm 0.3$ & 1.0 & 0.92 \\
{$[\mathrm{La}]_{\text {PEAK }}\left(\mathrm{mmol} \cdot \mathrm{L}^{-1}\right)$} & $12.7 \pm 2.5$ & $12.7 \pm 2.4$ & 0.0 & 1.00 \\
$\dot{V} \mathrm{O}_{2 \text { BASE }}\left(\mathrm{mL} \cdot \mathrm{kg}^{-1} \cdot \mathrm{min}^{-1}\right)$ & $5.2 \pm 0.8$ & $4.9 \pm 0.5$ & -6.1 & 0.11 \\
$\dot{V} \mathrm{O}_{2 \text { BASE }}\left(\mathrm{L} \cdot \mathrm{min}^{-1}\right)$ & $0.4 \pm 0.1$ & $0.4 \pm 0.1$ & -5.3 & 0.11 \\
$\dot{V} \mathrm{O}_{\text {2EX }}\left(\mathrm{mL} \cdot \mathrm{kg}^{-1} \cdot \mathrm{min}^{-1}\right)$ & $47.0 \pm 4.8$ & $46.6 \pm 4.5$ & -1.0 & 0.53 \\
$\dot{V} \mathrm{O}_{\text {2EX }}\left(\mathrm{L} \cdot \mathrm{min}^{-1}\right)$ & $3.7 \pm 0.5$ & $3.6 \pm 0.6$ & -0.9 & 0.63 \\
$\% \dot{ } \mathrm{V}_{2 \max }(\%)$ & $94.0 \pm 8.6$ & $93.1 \pm 9.1$ & -0.9 & 0.58 \\
\hline
\end{tabular}

Note: TTE, time limit to exhaustion in supramaximal test; $[\mathrm{La}]_{\mathrm{BASE}}$, resting blood lactate concentration; $[\mathrm{La}]_{\text {PEAK }}$, peak blood lactate concentration; $\dot{V} \mathrm{O}_{2 \mathrm{BASE}}$, resting oxygen uptake; $\dot{V} \mathrm{O}_{2 \mathrm{EX}}$, oxygen uptake at exhaustion point during TTE; \% $\dot{V} \mathrm{O}_{2 \max }$, percentage of maximal oxygen uptake reached by $\dot{\mathrm{V}} \mathrm{O}_{2 \mathrm{EX}}$.

dependent $t$ test for paired samples was used to verify the mean group differences and Pearson's correlation test to reveal associations between anaerobic capacity variables (both placebo and taurine supplemented conditions). The significance level was assumed as $95 \%$ for all cases $(p<0.05)$.

As an additional qualitative analysis, the magnitude of differences between groups was calculated and expressed as standardized mean differences (Cohen's $d$ ), which were calculated using the pooled standard deviations of the 2 testing sessions of interest (Cohen 1988). Threshold values for Cohen's $d$ statistics were $>0.2$ (small), $>0.5$ (moderate), and $>0.8$ (large). Confidence intervals (95\%) for the (true) between-group differences in the supplementation intervention response were estimated according to Hopkins et al. (2009). The chances of a possible substantial benefit or harm were calculated ( 0.2 multiplied by the between-subject deviation). Thus, the changes were qualitatively evaluated as follows: $<1 \%=$ most unlikely; $1 \%-$ $5 \%$ = very unlikely; $5 \%-25 \%$ = unlikely; $25 \%-75 \%$ = possibly; $75 \%-$ 95\% = likely; 95\%-99\% = very likely; and >99\% = most likely. When the positive and negative values were both $>5 \%$, the inference was classified as unclear (Hopkins et al. 2009).

\section{Results}

In all subjects at least 2 criteria for confirmation of the $\dot{V} \mathrm{O}_{2 \max }$ were verified in the treadmill-running test. The participants showed $\dot{V} \mathrm{O}_{2 \max }$ and $\mathrm{i} \dot{V} \mathrm{O}_{2 \max }$ values of $50.5 \pm 7.6 \mathrm{~mL} \cdot \mathrm{kg}^{-1} \cdot \mathrm{min}^{-1}$ and $14.0 \pm 1.2 \mathrm{~km} \cdot \mathrm{h}^{-1}$, respectively, and the incremental test lasted for $677.1 \pm 94.3 \mathrm{~s}$.

For supramaximal efforts, no statistical differences were observed for TTE, blood lactate responses, and $\mathrm{VO}_{2}$ variables, when comparing the acute placebo and taurine supplementation conditions (Table 1).

The qualitative analysis reveals a likely trivial effect of supplementation for TTE and the oxygen uptake at TTE $\left(\dot{V} \mathrm{O}_{\text {2EX }}\right)$. An unclear effect was found for blood lactate responses and percentage of $\dot{V} \mathrm{O}_{2 \max }$ reached by $\dot{V} \mathrm{O}_{2 \mathrm{Ex}}\left(\% \dot{\mathrm{V}} \mathrm{O}_{2 \max }\right)$ and likely negative effect was found for $\dot{V} \mathrm{O}_{2 \mathrm{BASE}}$ (Fig. 2).

Table 2 shows the values of $W_{[\mathrm{PCR}]}$ and $W_{[\mathrm{La}]}$ and MAOD $\mathrm{ALT}_{\mathrm{AL}}$ measured during both supramaximal efforts, as well as the percentage of change. No statistical differences were observed in any parameter when comparing the acute placebo and taurine supplementation conditions (Table 2).

The qualitative analyses also revealed an unclear effect for energetic contributions and for $\mathrm{MAOD}_{\mathrm{ALT}}$ when comparing the acute placebo and taurine supplementation conditions except for the phosphagen pathway, which was negatively influenced by acute taurine supplementation (possibly negative) (Fig. 3). 
Fig. 2. Chance of true effects of taurine supplementation on time to exhaustion (TTE), resting blood lactate concentration ([La $\left.]_{\mathrm{BASE}}\right)$, peak blood lactate concentration $\left([\mathrm{La}]_{\text {PEAK }}\right)$, resting oxygen uptake $\left(\dot{V} \mathrm{O}_{2 \mathrm{BASE}}\right)$, oxygen uptake at TTE $\left(\dot{\mathrm{V}} \mathrm{O}_{2 \mathrm{EX}}\right)$, and percentage of maximal oxygen uptake reached by $\dot{V O}_{2 \mathrm{EX}}\left(\% \dot{V O}_{2 \max }\right)$.

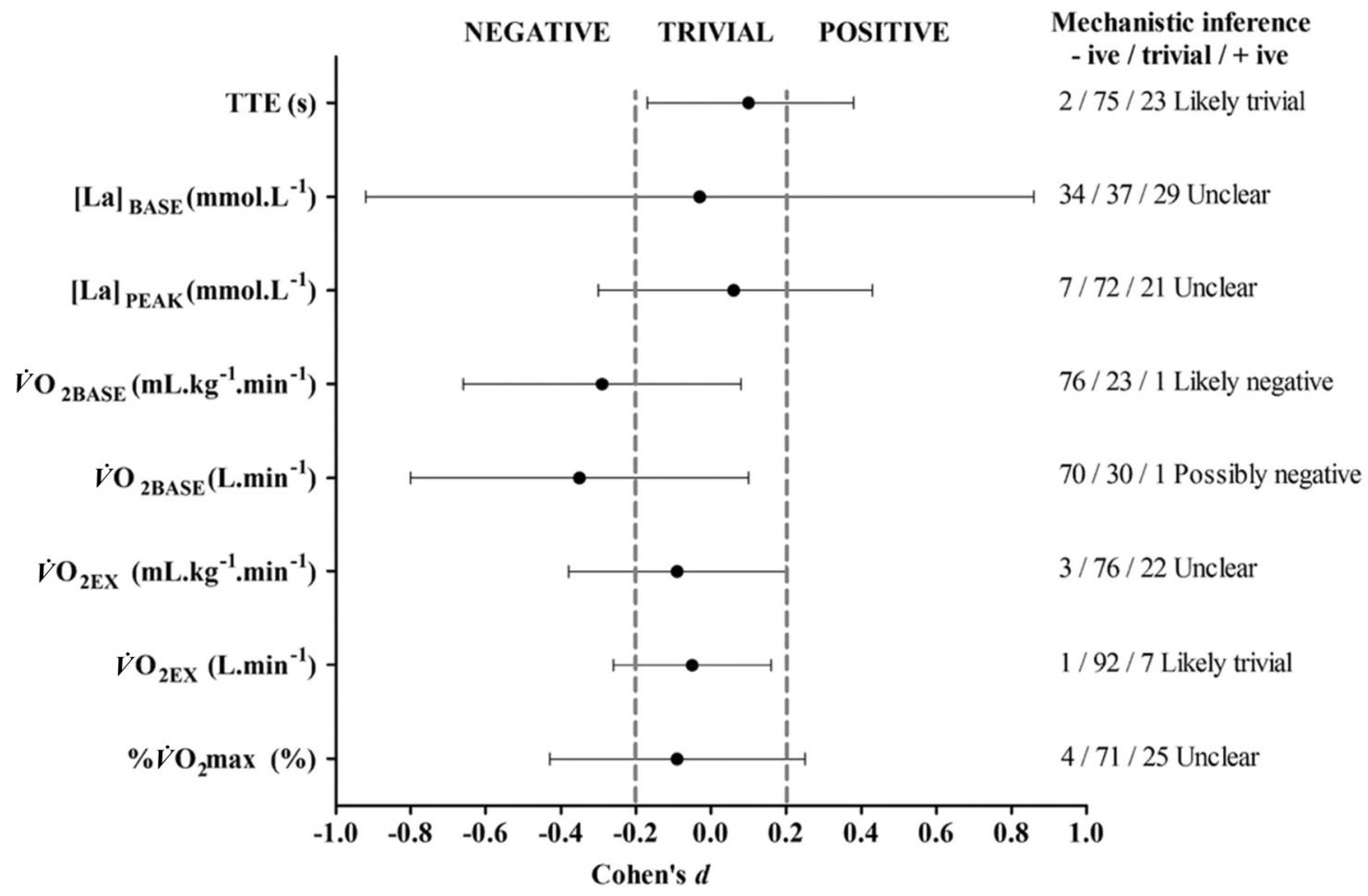

Table 2. Mean \pm SD of phosphagen and glycolytic systems and $\mathrm{MAOD}_{\mathrm{ALT}}$ measured during supramaximal efforts under placebo and taurine supplementation.

\begin{tabular}{|c|c|c|c|c|}
\hline & Placebo & Taurine & $\%$ & $p$ \\
\hline$W_{[\mathrm{PCR}]}\left(\mathrm{mL} \cdot \mathrm{kg}^{-1}\right)$ & $20.7 \pm 2.9$ & $20.0 \pm 3.2$ & -3.5 & 0.36 \\
\hline$W_{[\text {PCR }]}(\mathrm{L})$ & $1.6 \pm 0.3$ & $1.6 \pm 0.3$ & -3.9 & 0.31 \\
\hline$W_{[\mathrm{La}]}\left(\mathrm{mL} \cdot \mathrm{kg}^{-1}\right)$ & $35.1 \pm 7.6$ & $35.0 \pm 7.2$ & -0.1 & 0.98 \\
\hline$W_{[\text {La] }}(\mathrm{L})$ & $2.7 \pm 0.5$ & $2.7 \pm 0.5$ & 0.0 & 0.90 \\
\hline $\mathrm{MAOD}_{\mathrm{ALT}}\left(\mathrm{mL} \cdot \mathrm{kg}^{-1}\right)$ & $55.8 \pm 8.2$ & $55.1 \pm 7.9$ & -1.3 & 0.61 \\
\hline $\mathrm{MAOD}_{\mathrm{ALT}}(\mathrm{L})$ & $4.3 \pm 0.7$ & $4.3 \pm 0.7$ & -1.2 & 0.65 \\
\hline
\end{tabular}

\section{Discussion}

The aim of the present study was to investigate the influence of a high acute dose of taurine on TTE of supramaximal running and on $\mathrm{MAOD}_{\mathrm{ALT}}$. The main findings were the nonstatistical effects of acute taurine ingestion, the trivial effect on TTE, and the unclear effect on anaerobic capacity parameters such as $\mathrm{MAOD}_{\mathrm{ALT}}, W_{\text {[La], }}$, $W_{[\mathrm{PCR}]}$, and peak blood lactate concentration using magnitudebased inference analysis.

In line with this study, other recent studies did not show any ergogenic effects of taurine supplementation in different forms of exercise (Pettitt et al. 2013). Pettitt et al. (2013) did not show improvements in the aerobic metabolism (accumulated oxygen consumed and EPOC) after acute ingestion of an energy drink (caffeine + taurine) or control drink (equivalent caffeine content alone).

To our knowledge few studies have investigated the effects of acute taurine supplementation on anaerobic parameters. Alford et al. (2001) found positive effects of acute administration of an energy drink with taurine on a 20-s all-out cycling exercise (i.e., maintaining the maximal velocity achieved for $\sim 1.4 \mathrm{~s}$ longer than the control condition). On the other hand, Gwacham and Wagner (2012) did not find improvements in anaerobic power or sprint performance in a repeated sprint ability test (i.e., Running Anaerobic Sprint Test) after acute administration of a caffeine-taurine drink; similarly, Astorino et al. (2012) did not find significant effects of 1 serving of an energy drink (caffeine + taurine) on repeated sprint ability time-performance in female soccer players.

Previous studies have reported possible beneficial effects of acute taurine supplementation on mood state, alertness, and reaction time of some cognitive tasks (Ivy et al. 2009; Giles et al. 2012), which could contribute to reduce the perception of effort and reaction time (Ivy et al. 2009). Taken together, the other taurine physiological mechanisms (i.e., decrement of oxidative stress (Miyazaki et al. 2004), increase of $\mathrm{Ca}^{2+}$ release on muscle cells (Dutka et al. 2014), and stabilization and hyperexcitement of the cell membrane (Yatabe et al. 2003)), the acute taurine supplementation might contribute to high-intensity exercise performance. However, this effect appears to be linked with taurine content of muscle cells (Galloway et al. 2008; Balshaw et al. 2013), and even a high dose of acute supplementation of taurine does not ensure the bioavailability on muscle cells, especially on type II fibers (Galloway et al. 2008).

Still, despite the fact that the mechanisms by which taurine enhances performance are related to muscle taurine level content, it could also be connected with prior training status. It has previously been shown that endurance-trained individuals have higher absolute taurine muscle content than untrained individuals (Graham et al. 1995; Blomstrand and Saltin 1999). The taurine content in the cells of the central nervous system plays an important role in modulating neuronal excitability (Lehmann et al. 1984) and elevating neurotransmitter levels (e.g., glutamate and gamma-aminobutyric acid) (El Idrissi and Trenkner 2004). Furthermore, Balshaw et al. (2013) verified improvements in a 3-km time trial in well-trained, middle-distance runners (i.e., $800-\mathrm{m}$ personal best $=121.0 \pm 5.3 \mathrm{~s})$ after acute $1 \mathrm{~g}$ taurine ingestion $(99.3 \%$ beneficial effects of taurine ingestion), and Dutka et al. (2014) showed in human muscle cells that after $>10$ min of taurine ex- 
Fig. 3. Chance of true effects of taurine supplementation on energetic contributions of phosphagen pathway $\left(W_{[\mathrm{PCR}]}\right)$, glycolytic pathway $\left(W_{\text {[La] }}\right)$, and alternative maximal accumulated oxygen deficit $\left(\mathrm{MAOD}_{\mathrm{ALT}}\right)$.

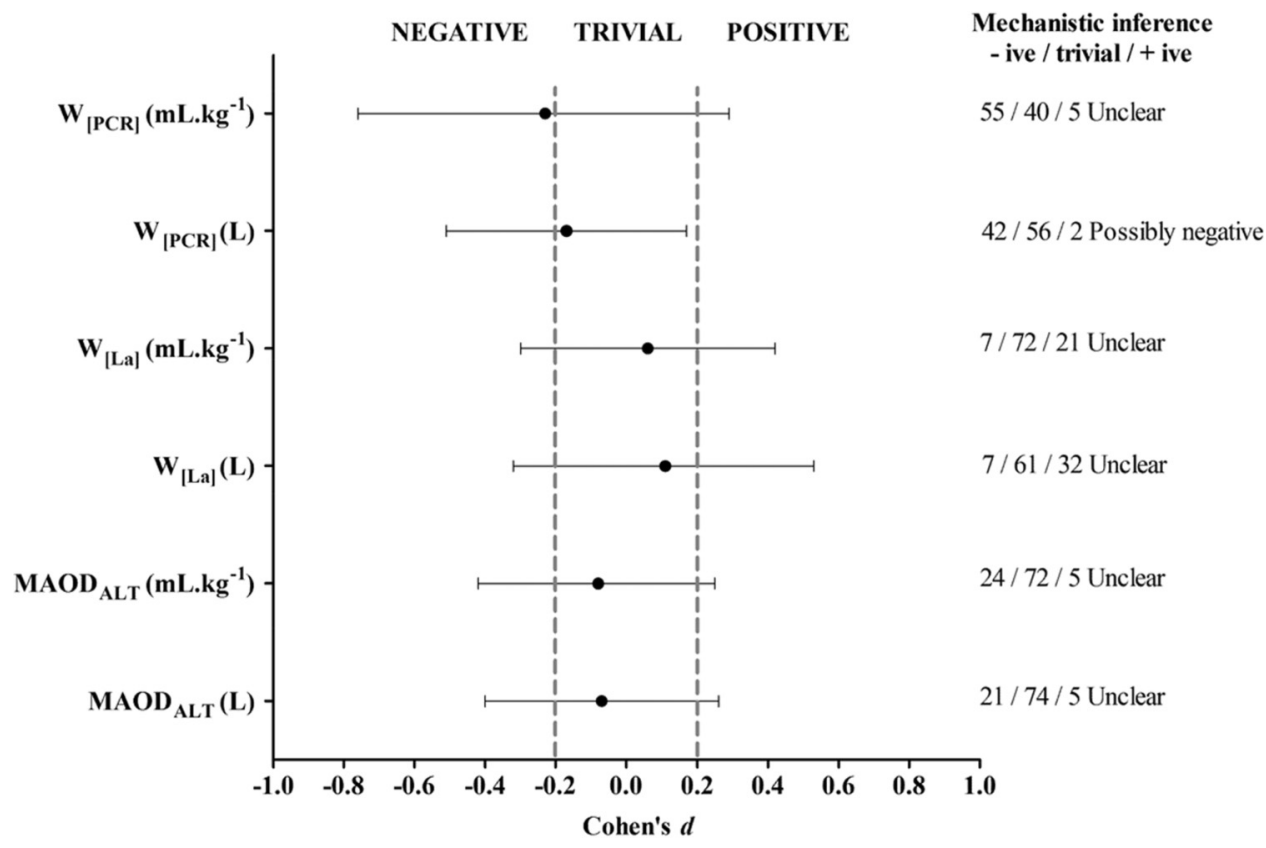

position there was an improvement in $\mathrm{Ca}^{2+}$ release from the sarcoplasmic reticulum. The combined results of these papers (Balshaw et al. 2013; Dutka et al. 2014) suggest that the chronic administration of taurine (i.e., higher than 7-days) in combination with aerobic training may be effective to increase the intramuscular content of taurine. Consequently, this strategy could improve the $\mathrm{Ca}^{2+}$ release by the sarcoplasmic reticulum and generate a beneficial effect on strength/power production and enhancing sports performance.

In this way a chronic taurine supplementation (i.e., 7 days of supplementation) plus aerobic training could prevent a significant decrement of muscle taurine content, and contribute to maintenance of muscle cell membrane integrity (Miyazaki et al. 2004) and performance improvement (Yatabe et al. 2003).

The absence of muscle tissue analysis to investigate intracellular taurine content after acute high-dosage supplementation is a limitation of the present study. Further studies should consider the effects of different taurine supplementation periods in individuals with different physical fitness levels (aerobic and anaerobic), using more sophisticated techniques for the evaluation of biomolecular mechanisms.

In conclusion, acute $6 \mathrm{~g}$ of taurine supplementation before exercise did not substantially improve high-intensity running performance and showed an unclear effect on $\mathrm{MAOD}_{\mathrm{ALT}}$.

\section{Conflict of interest statement}

The authors declare that there are no conflicts of interest.

\section{Acknowledgements}

Funding for the study was provided by Foundation of Research Support of São Paulo State (FAPESP - protocol no. 2013/12940-8). Special thanks go to all the participants for their amazing dedication.

\section{References}

Alford, C., Cox, H., and Wescott, R. 2001. The effects of red bull energy drink on human performance and mood. Amino Acids, 21(2): 139-150. doi:10.1007/ s007260170021. PMID:11665810.

Astorino, T.A., Martin, B.J., Wong, K., and Schachtsiek, L. 2009. Effect of acute caffeine ingestion on EPOC after intense resistance training. Med. Sci. Sports Exerc. 41(5): 108. doi:10.1249/01.mss.0000353614.65748.39.

Astorino, T.A., Matera, A.J., Basinger, J., Evans, M., Schurman, T., and
Marquez, R. 2012. Effects of red bull energy drink on repeated sprint performance in women athletes. Amino Acids, 42(5): 1803-1808. doi:10.1007/s00726011-0900-8. PMID:21461905.

Baker, L.B., Rollo, I., Stein, K.W., and Jeukendrup, A.E. 2015. Acute Effects of Carbohydrate Supplementation on Intermittent Sports Performance. Nutrients, 7(7): 5733-5763. doi:10.3390/nu7075249. PMID:26184303.

Balshaw, T.G., Bampouras, T.M., Barry, T.J., and Sparks, S.A. 2013. The effect of acute taurine ingestion on $3-\mathrm{km}$ running performance in trained middledistance runners. Amino Acids, 44(2): 555-561. doi:10.1007/s00726-012-1372-1. PMID:22855206.

Bertuzzi, R.C., Franchini, E., Ugrinowitsch, C., Kokubun, E., Lima-Silva, A.E., Pires, F.O., Nakamura, F.Y., and Kiss, M.A. 2010. Predicting MAOD using only a supramaximal exhaustive test. Int. J. Sports. Med. 31(7): 477-481. doi:10.1055/ s-0030-1253375. PMID:20432195.

Blomstrand, E., and Saltin, B. 1999. Effect of muscle glycogen on glucose, lactate and amino acid metabolism during exercise and recovery in human subjects. J. Physiol. 514 (Pt. 1): 293-302. doi:10.1111/j.1469-7793.1999.293af.x. PMID:9831734.

Brisola, G.M., Miyagi, W.E., da Silva, H.S., and Zagatto, A.M. 2015. Sodium bicarbonate supplementation improved MAOD but is not correlated with 200-and 400-m running performances: a double-blind, crossover, and placebo-controlled study. Appl. Physiol. Nutr. Metab. 40(9): 931-937. doi:10.1139/apnm-2015-0036. PMID:26300016.

Cohen, J. 1988. Statistical power analysis for the behavioral sciences. Hillsdale: Lawrence Erlbaum.

da Silva, L.A., Tromm, C.B., Bom, K.F., Mariano, I., Pozzi, B., da Rosa, G.L., Tuon, T., da Luz, G., Vuolo, F., Petronilho, F., et al. 2014. Effects of taurine supplementation following eccentric exercise in young adults. Appl. Physiol. Nutr. Metab. 39(1): 101-104. doi:10.1139/apnm-2012-0229. PMID:24383513.

De Pauw, K., Roelands, B., Cheung, S.S., de Geus, B., Rietjens, G., and Meeusen, R. 2013. Guidelines to classify subject groups in sport-science research. Int. J. Sports Physiol. Perform. 8(2): 111-122. PMID:23428482.

di Prampero, P.E., and Ferretti, G. 1999. The energetics of anaerobic muscle metabolism: a reappraisal of older and recent concepts. Respir. Physiol. 118(2-3): 103-115. doi:10.1016/S0034-5687(99)00083-3. PMID:10647856.

Dutka, T.L., Lamboley, C.R., Murphy, R.M., and Lamb, G.D. 2014. Acute effects of taurine on sarcoplasmic reticulum Ca2+ accumulation and contractility in human type I and type II skeletal muscle fibers. J. Appl. Physiol. (1985), 117(7): 797-805. doi:10.1152/japplphysiol.00494.2014. PMID:25123198.

El Idrissi, A., and Trenkner, E. 2004. Taurine as a modulator of excitatory and inhibitory neurotransmission. Neurochem. Res. 29(1): 189-197. doi:10.1023/B: NERE.0000010448.17740.6e. PMID:14992278.

Galloway, S.D., Talanian, J.L., Shoveller, A.K., Heigenhauser, G.J., and Spriet, L.L. 2008. Seven days of oral taurine supplementation does not increase muscle taurine content or alter substrate metabolism during prolonged exercise in humans. J. Appl. Physiol. (1985), 105(2): 643-651. doi:10.1152/japplphysiol. 90525.2008. PMID:18583380.

Geiß, K.R., Jester, I., Falke, W., Hamm, M., and Waag, K.L. 1994. The effect of a 
taurine-containing drink on performance in 10 endurance-athletes. Amino Acids, 7(1): 45-56. doi:10.1007/BF00808445. PMID:24185972.

Giles, G.E., Mahoney, C.R., Brunyé, T.T., Gardony, A.L., Taylor, H.A., and Kanarek, R.B. 2012. Differential cognitive effects of energy drink ingredients: caffeine, taurine, and glucose. Pharmacol. Biochem. Behav. 102(4): 569-577. doi:10.1016/j.pbb.2012.07.004. PMID:22819803.

Graham, T.E., Turcotte, L.P., Kiens, B., and Richter, E.A. 1995. Training and muscle ammonia and amino acid metabolism in humans during prolonged exercise. J. Appl. Physiol. (1985), 78(2): 725-735. PMID:7759446.

Gwacham, N., and Wagner, D.R. 2012. Acute effects of a caffeine-taurine energy drink on repeated sprint performance of American college football players. Int. J. Sport. Nutr. Exerc. Metab. 22(2): 109-116. PMID:22349209.

Hopkins, W.G., Marshall, S.W., Batterham, A.M., and Hanin, J. 2009. Progressive statistics for studies in sports medicine and exercise science. Med. Sci. Sports Exerc. 41(1): 3-13. doi:10.1249/MSS.0b013e31818cb278. PMID:19092709.

Howley, E.T., Bassett, D.R., Jr., and Welch, H.G. 1995. Criteria for maximal oxygen uptake: review and commentary. Med. Sci. Sports Exerc. 27(9): 1292-1301. PMID:8531628.

Imagawa, T.F., Hirano, I., Utsuki, K., Horie, M., Naka, A., Matsumoto, K., and Imagawa, S. 2009. Caffeine and taurine enhance endurance performance. Int. J. Sports. Med. 30(7): 485-488. doi:10.1055/s-0028-1104574. PMID:19455480.

Ivy, J.L., Kammer, L., Ding, Z., Wang, B., Bernard, J.R., Liao, Y.H., and Hwang, J. 2009. Improved cycling time-trial performance after ingestion of a caffeine energy drink. Int. J. Sport Nutr. Exerc. Metab. 19(1): 61-78. PMID:19403954.

Lehmann, A., Hagberg, H., and Hamberger, A. 1984. A role for taurine in the maintenance of homeostasis in the central nervous system during hyperexcitation? Neurosci. Lett. 52(3): 341-346. doi:10.1016/0304-3940(84)90185-X. PMID:6395048.

Medbø, J.I., Mohn, A.C., Tabata, I., Bahr, R., Vaage, O., and Sejersted, O.M. 1988. Anaerobic capacity determined by maximal accumulated $\mathrm{O}_{2}$ deficit. J. Appl. Physiol. (1985), 64(1): 50-60. PMID:3356666.

Miyazaki, T., Matsuzaki, Y., Ikegami, T., Miyakawa, S., Doy, M., Tanaka, N., and Bouscarel, B. 2004. Optimal and effective oral dose of taurine to prolong exercise performance in rat. Amino Acids, 27(3-4): 291-298. doi:10.1007/s00726004-0133-1. PMID:15503230.

Noordhof, D.A., de Koning, J.J., and Foster, C. 2010. The maximal accumulated oxygen deficit method: a valid and reliable measure of anaerobic capacity? Sports Med. 40(4): 285-302. doi:10.2165/11530390-000000000-00000. PMID: 20364874
Noordhof, D.A., Vink, A.M., de Koning, J.J., and Foster, C. 2011. Anaerobic capacity: effect of computational method. Int. J. Sports. Med. 32(6): 422-428. doi: 10.1055/s-0031-1271676. PMID:21563025.

Özyener, F., Rossiter, H.B., Ward, S.A., and Whipp, B.J. 2001. Influence of exercise intensity on the on- and off-transient kinetics of pulmonary oxygen uptake in humans. J. Physiol. 533(3): 891-902. doi:10.1111/j.1469-7793.2001.t01-1-00891.x.

Pettitt, R.W., Niemeyer, J.D., Sexton, P.J., Lipetzky, A., and Murray, S.R. 2013. Do the noncaffeine ingredients of energy drinks affect metabolic responses to heavy exercise? J. Strength Cond. Res. 27(7): 1994-1999. doi:10.1519/JSC. 0b013e3182736e31. PMID:23037611.

Rutherfod, J.A., Spriet, L.L., and Stellingwerff, T. 2010. The effect of acute taurine ingestion on endurance performance and metabolism in well-treined cyclists. Int. J. Sports. Nutr. Exerc. Metab. 20(4): 322-329. PMID:20739720.

Stellingwerff, T., and Cox, G.R. 2014. Systematic review: Carbohydrate supplementation on exercise performance or capacity of varying durations. Appl. Physiol. Nutr. Metab. 39(9): 998-1011. doi:10.1139/apnm-2014-0027.

Walsh, A.L., Gonzalez, A.M., Ratamess, N.A., Kang, J, and Hoffman, J.R. 2010. Improved time to exhaustion following ingestion of the energy drink Amino Impact. J. Int. Soc. Sports Nutr. 7: 14. doi:10.1186/1550-2783-7-14. PMID: 20398312.

Weber, C.L., and Schneider, D.A. 2001. Reliability of MAOD measured at $110 \%$ and $120 \%$ of peak oxygen uptake for cycling. Med. Sci. Sports Exerc. 33(6): 10561059. doi:10.1097/00005768-200106000-00028. PMID:11404674.

Yatabe, Y., Miyakawa, S., Miyazaki, T., Matsuzaki, Y., and Ochiai, N. 2003. Effects of taurine administration in rat skeletal muscles on exercise. J. Orthop. Sci. 8(3): 415-419. doi:10.1007/s10776-002-0636-1. PMID:12768487.

Zagatto, A.M., and Gobatto, C.A. 2012. Relationship between anaerobic parameters provided from MAOD and critical power model in specific table tennis test. Int. J. Sports. Med. 33(8): 613-620. doi:10.1055/s-0032-1304648. PMID: 22562729.

Zagatto, A., Redkva, P., Loures, J., Kalva Filho, C., Franco, V., Kaminagakura, E., and Papoti, M. 2011. Anaerobic contribution during maximal anaerobic running test: correlation with maximal accumulated oxygen deficit. Scand J. Med. Sci. Sports, 21(6): e222-e230. doi:10.1111/j.1600-0838.2010.01258.x.

Zhang, M., Izumi, I., Kagamimori, S., Sokejima, S., Yamagami, T., Liu, Z., and Qi, B. 2004. Role of taurine supplementation to prevent exercise-induced oxidative stress in healthy young men. Amino Acids, 26(2): 203-207. doi:10. 1007/s00726-003-0002-3. PMID:15042451. 